\title{
Ouabain Effects on Oxygen Physiology in Anemic Lambs
}

\author{
WILLIAM BERMAN, JR., GEORGE LISTER, JR., DALE ALVERSON, AND STEVE OLSEN \\ Departments of Pediatrics, University of New Mexico, Albuquerque, New Mexico and Yale University, New \\ Haven, Connecticut
}

\begin{abstract}
We studied the effects of anemia and ouabain administration on cardiac function, oxygen physiology, and blood catecholamine levels in nine newborn lambs. We measured oxygen consumption continuously, along with traditional hemodynamic variables. Oxygen transport was calculated. Following baseline measurements, lambs were made anemic (mean hematocrit $=12 \%$ ) by isovolemic exchange transfusion with Plasmanate, and measurements were repeated. Thereafter ouabain was administered as a $75 \mu \mathrm{g} / \mathrm{kg}$ bolus, followed by $30 \mathrm{~min}$ of infusion at a rate of $0.05 \mu \mathrm{g} / \mathrm{kg} / \mathrm{min}$. Measurements were repeated at the conclusion of infusion. Anemia was associated with a heart rate related rise in left ventricular rate of pressure rise, a rise in oxygen consumption, an increase in cardiac output, a decrease in systemic vascular resistance, and a rise in fractional oxygen extraction (oxygen consumption/transport). Following ouabain administration, cardiac output, oxygen consumption, and stroke work fell, but left ventricular rate of pressure rise and the extraction ratio did not change. Serum levels of epinephrine and norepinephrine rose with sustained anemia and ouabain infusion. In this setting, ouabain effects are manifested primarily by alterations in oxygen transport and metabolism rather than by changes in traditional assessments of left ventricular contractile function. (Pediatr Res 21: 447-452, 1987)
\end{abstract}

\section{Abbreviations}

$L V$, left ventricle

$\mathrm{dP} / \mathrm{dt}$, rate of pressure rise

PEP, preejection period

ET, ejection time

$\mathrm{VO}_{2}$, oxygen consumption

$\mathrm{A}-\mathrm{V}$, arterial-venous

SOT, systemic oxygen transport

SVR, systemic vascular resistance

Cardiac glycosides are used commonly to treat circulatory congestion in infants and children with congenital cardiac defects $(1-3)$. Traditionally, the weight-related doses of digoxin used in immature subjects are higher than those used in adults $(4,5)$, although the reasons for that practice remain unclear (6-10). Moreover, because the high resting level of myocardial muscle function early in life may not be affected adversely by structural cardiac defects (11-14), some have questioned the appropriateness of inotropic therapy for this patient group. Nevertheless,

Received November 19, 1984; accepted December 8, 1986

Reprint address William Berman, Jr., M.D., Department of Pediatrics, University of New Mexico, School of Medicine, Albuquerque, NM 87131. clinical impression and a few selected studies suggest that young subjects with structural cardiac defects benefit from cardiac glycoside therapy (15-17), although the precise mechanism of the effect has not been established (18-20).

Despite the presence of vigorous myocardial muscle function with many congenital cardiac defects, the congested circulatory state can perturb oxygen transport to the tissues $(15,21)$. It is possible that in this setting cardiac glycosides may exert their predominant influence on the peripheral supply and demand for oxygen through their effect on the energy requiring sodiumpotassium ATPase pump enzyme system. In the present study we created circulatory conditions characterized by normal to increased myocardial function, yet compromised systemic oxygen transport by inducing anemia in conscious newborn lambs. It was our purpose to test the effects of ouabain on both myocardial function and systemic oxygen transport under these conditions.

\section{METHODS}

Studies were performed in 13 newborn lambs within the 1 st wk of life. Animals were blindfolded, restrained in a sling, and given local anesthesia with $1 \%$ xylocaine to permit insertion of central venous and aortic polyvinyl catheters (OD 0.090 in, ID 0.050 in) via the right femoral vein and artery, a 5 French left ventricular manometric-tipped catheter inserted retrograde via the carotid artery, and ECG electrodes into the chest wall. Sedation and general anesthesia were not administered during the 3-4 h of study. Animals were kept normothermic $\left(39^{\circ} \mathrm{C}\right)$ by the use of a heating pad. During the study, the following measurements were made: aortic, right atrial and LV pressure; arterial hematocrit and hemoglobin concentration; heart rate (via a Beckman 9857 cardiotachometer); ECG, LV dP/dt (via a Beckman 9879 differentiating circuit); LV PEP and LVET by methods described previously (11); right atrial and aortic oxygen saturations (Radiometer OMII, Copenhagen, Denmark) and blood gas tensions (at $37^{\circ} \mathrm{C}$ ); $\mathrm{VO}_{2}$, measured continuously by the flow through method (22); and serum levels of epinephrine and norepinephrine (CAT-A-KIT ASSAY, Upjohn Diagnostics, Kalamazoo, MI) (23). From the measured variables, the following data were calculated: mixed venous and arterial oxygen contents (as the sum of dissolved and hemoglobin-bound $\mathrm{O}_{2}$ ); the A-V $\mathrm{O}_{2}$ content difference; cardiac output (according to the Fick principle); SOT (cardiac output $\times$ arterial oxygen content); SVR (systemic perfusion pressure/cardiac output); the PEP/LVET ratio; the fractional oxygen extraction $\left(\mathrm{VO}_{2} / \mathrm{SOT}\right)$; and base deficit.

Baseline measurements in nine study animals were made $1 \mathrm{~h}$ following instrumentation. Then animals were made anemic by phlebotomy and isovolemic, warmed Plasmanate replacement in $50-\mathrm{ml}$ increments (total volume varied between 300 and 550 $\mathrm{ml}$ to achieve the desired level of anemia). $\mathrm{VO}_{2}$ was measured continuously and hemodynamic data were recorded periodically 
until the arterial hematocrit fell below $15 \%$. Thirty min after completion of blood removal, measurements were repeated. Ouabain was then given as a bolus dose of $75 \mu \mathrm{g} / \mathrm{kg}$ followed by a continuous infusion of $0.05 \mu \mathrm{g} / \mathrm{kg} / \mathrm{min}$ (19). Following a $30-$ min infusion period, measurements were repeated again. Animals were killed by pentobarbital overdose.

Additional studies were performed on four other lambs (mean age $5.2 \pm 0.5$ days, mean weight $5.8 \pm 0.6 \mathrm{~kg}$ ) for two reasons: 1) to verify the stability of hemodynamic changes caused by a level of anemia comparable to that of the study animals and 2) to determine the effects of progressive levels of anemia on hemodynamic and oxygen transport variables. One hour following instrumentation, baseline measurements were made. The animals were then made anemic over $30 \mathrm{~min}$ by phlebotomy with Plasmanate replacement in 50-ml increments. Thirty min and $2 \mathrm{~h}$ later, measurements were repeated. Additional blood removal with volume replacement was then performed to reduce arterial hematocrit below $10 \%$. One h later measurements were repeated and the animals were killed. Data were compared by

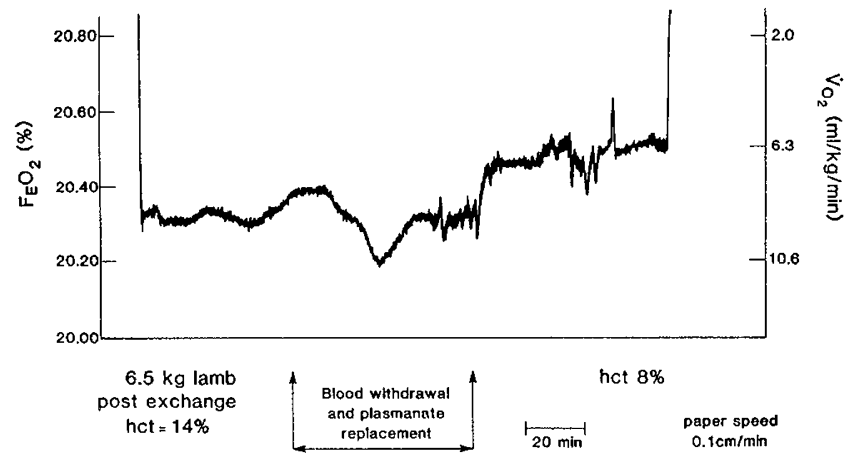

Fig. 1. Slow speed tracing of $\mathrm{VO}_{2}$ during staged induction of anemia in one of four control group lambs. The ordinate scale is expressed both as percent expired oxygen $\left(\mathrm{F}_{E} \mathrm{O}_{2}\right)$ and $\mathrm{VO}_{2}$. The baseline $\mathrm{VO}_{2}$ in this study was $9.2 \mathrm{ml} / \mathrm{kg} / \mathrm{min}$. The fall in $\mathrm{VO}_{2}$ following reduction of the hematocrit ( $h c t$ ) from 14 to $8 \%$ is evident.

Table 1. Physiologic effects of anemia (mean $\pm S D)^{*}$

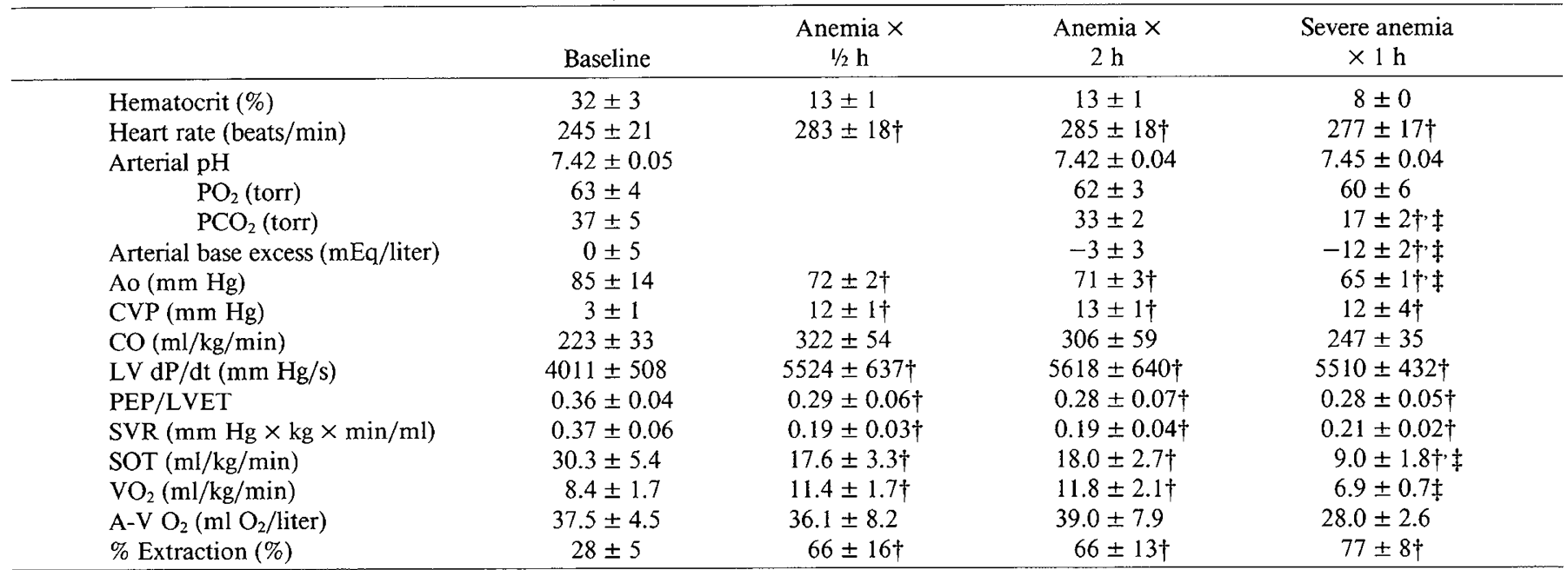

*Ao, mean aortic pressure; CVP, mean central venous pressure; CO, cardiac output; \% extraction, \% extraction of oxygen from arterial blood $\left(\mathrm{VO}_{2} / \mathrm{SOT}\right) ; \mathrm{Hg}$, hemoglobin.

$\dagger$ Differs from baseline, $p<0.05$.

$\ddagger$ Differs from anemia $\times 2 \mathrm{~h}, p<0.05$.

Table 2. Hemodynamic effects of intervention (mean $\pm S D)^{*}$

\begin{tabular}{|c|c|c|c|}
\hline & Baseline & Anemia & Anemia + ouabain \\
\hline Hematocrit $(\%)$ & $38 \pm 4$ & $12 \pm 2 \dagger$ & $12 \pm 2 \dagger$ \\
\hline Heart rate (beats/min) & $225 \pm 25$ & $270 \pm 28$ & $255 \pm 37$ \\
\hline Arterial pH & $7.41 \pm 0.02$ & $7.44 \pm 0.03$ & $7.39 \pm 0.03 \ddagger$ \\
\hline $\mathrm{PCO}_{2}$ (torr) & $35 \pm 2$ & $32 \pm 2 \dagger$ & $34 \pm 3 \ddagger$ \\
\hline Arterial base excess (mEq/liter) & $-2 \pm 2$ & $-3 \pm 2$ & $-4 \pm 2$ \\
\hline Ao $(\mathrm{mm} \mathrm{Hg})$ & $97 \pm 18$ & $87 \pm 13$ & $83 \pm 14$ \\
\hline $\mathrm{LV} \mathrm{dP} / \mathrm{dt}(\mathrm{mm} \mathrm{Hg} / \mathrm{s})$ & $4061 \pm 602$ & $5689 \pm 667 \dagger$ & $5711 \pm 757 \dagger$ \\
\hline $\mathrm{SW}(\mathrm{mm} \mathrm{Hg} \times$ liter $/ \mathrm{kg} / \mathrm{min})$ & $22.4 \pm 9.6$ & $36.6 \pm 16.2 \dagger$ & $24.7 \pm 12.7 \ddagger$ \\
\hline PEP/LVET & $0.36 \pm 0.04$ & $0.29 \pm 0.06 \dagger$ & $0.27 \pm 0.02 \dagger$ \\
\hline $\operatorname{SVR}(\mathrm{mm} \mathrm{Hg} \times \mathrm{kg} \times \mathrm{min} / \mathrm{ml})$ & $0.45 \pm 0.18$ & $0.23 \pm 0.12 \dagger$ & $0.30 \pm 0.17 \dagger$ \\
\hline $\mathrm{SOT}(\mathrm{ml} / \mathrm{kg} / \mathrm{min})$ & $32.7 \pm 12.9$ & $19.6 \pm 4.0 \dagger$ & $13.9 \pm 4.3 \dagger$ \\
\hline $\mathrm{VO}_{2}(\mathrm{ml} / \mathrm{kg} / \mathrm{min})$ & $9.28 \pm 1.22$ & $12.86 \pm 2.12 \dagger$ & $8.40 \pm 1.39 \ddagger$ \\
\hline
\end{tabular}

*Ao, mean aortic pressure; CVP, mean central venous pressure; $\mathrm{CO}$, cardiac output; SW, stroke work; \% extraction, $\%$ extraction of oxygen from arterial blood; epi, epinephrine; $\mathrm{n}$-epi, norepinephrine; $\mathrm{Hg}$, hemoglobin.

$\dagger$ Differs from baseline, $p<0.05$.

$\ddagger$ Differs from anemia, $p<0.05$. 
an analysis of variance and the Scheffe test of significance (24). $p<0.05$ was considered statistically significant.

\section{RESULTS}

Anemia to hematocrit levels of $12-15 \%$ produced stable hemodynamic alterations in the four control animals over a 2-hr observation period (Table 1). Both 30 and 120 min following completion of blood removal and isovolemic Plasmanate replacement, heart rate, cardiac output, central venous pressure, and oxygen consumption rose; systemic oxygen transport, aortic mean pressure, and systemic vascular resistance fell. Although the A-V oxygen content difference did not change from control levels, the fractional extraction of oxygen from arterial blood $\left(\mathrm{VO}_{2} / \mathrm{SOT}\right)$ rose markedly. The subsequent reduction of hematocrit to levels less than $10 \%$ (mean $8 \%$ ) resulted in a marked fall in oxygen consumption, oxygen transport, and base buffering capacity and a further rise in percent oxygen extraction (Table 1, Fig. 1).

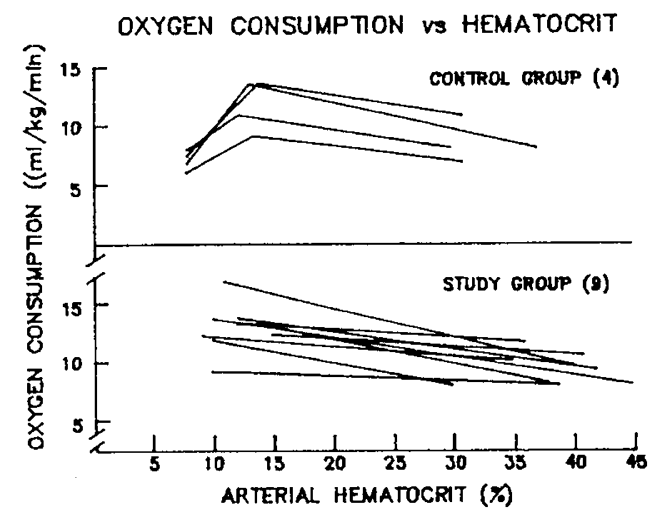

LEFT VENTRICULAR $d P / d t$ VS HEMATOCRIT

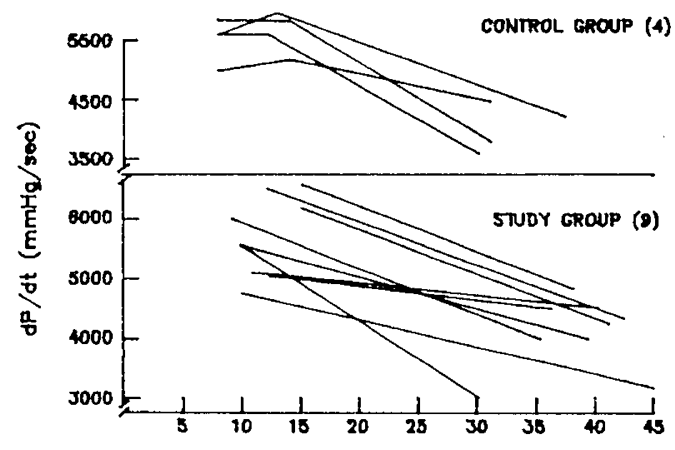

ARTERIAL HEMATOCRIT (x)

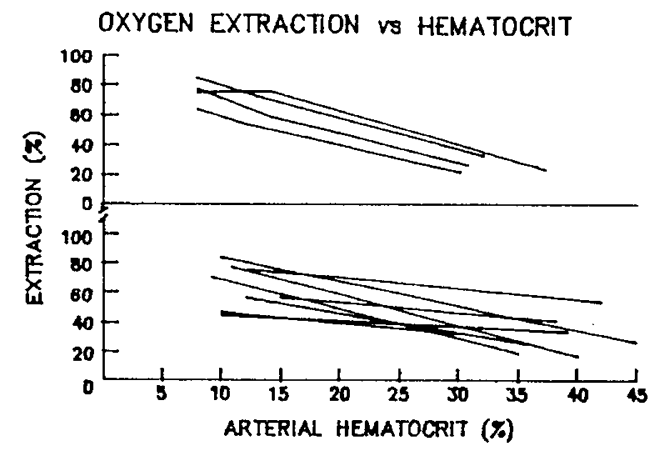

Fig. 2. The relationship of arterial hematocrit to $\mathrm{VO}_{2}, \mathrm{LV} \mathrm{dP} / \mathrm{dt}$, and arterial oxygen extraction in four control and nine study group animals. The anemia related rise in $\mathrm{LV} \mathrm{dP} / \mathrm{dt}$ and oxygen extraction is in contrast to the rise and subsequent fall of $\mathrm{VO}_{2}$ following reduction of hematocrit to values under $10 \%$ in the four control group lambs.
The nine study lambs weighed $5.4 \pm 1.0 \mathrm{~kg}$ when studied at $5.1 \pm 1.9$ days of age. Baseline hemodynamic data are shown in Table 2. Following phlebotomy, mean arterial hematocrit fell from 38 to $12 \%$. As with the control lambs during anemia, mean cardiac output rose (from 226 to $398 \mathrm{ml} / \mathrm{kg} / \mathrm{min}$ ). There was a heart rate-related rise in $\mathrm{LV} \mathrm{dP/dt}$ and a fall in the PEP/LVET ratio. $\mathrm{VO}_{2}$, the fractional oxygen extraction $\left(\mathrm{VO}_{2} / \mathrm{SOT}\right)$, and stroke work rose; systemic oxygen transport and vascular resistance fell. Serum levels of norepinephrine rose, but serum epinephrine levels were not significantly altered. Figure 2 shows the effects of anemia on $\mathrm{VO}_{2}, \mathrm{LV} \mathrm{dP} / \mathrm{dt}$, and oxygen extraction in the nine study and four control lambs.

Following ouabain infusion, hematocrit, heart rate, the A-V $\mathrm{O}_{2}$ content difference, $\mathrm{LV} \mathrm{dP/dt}$, the $\mathrm{PEP} / \mathrm{LVET}$ ratio, and SVR did not change significantly. $\mathrm{VO}_{2}$, cardiac output, and stroke work fell. Neither Oxygen extraction nor base deficit changed significantly. The serum levels of epinephrine and norepinephrine rose. Serum $\mathrm{pH}$ fell slightly, but significantly.

Figure 3 shows tracings from a 6-day-old, 4.5-kg lamb. Rhythmic variations in tracings with anemia and anemia plus ouabain are due to the increased respiratory efforts of the anemic animals (25). The anemia-related rise in heart rate, $\mathrm{LV} \mathrm{dP} / \mathrm{dt}$, and $\mathrm{VO}_{2}$, as well as the ouabain related fall in $\mathrm{VO}_{2}$, are seen

\section{6 day old, $4.5 \mathrm{~kg}$ lamb}

\begin{tabular}{|c|c|c|}
\hline CONTROL & ANEMIA & $\begin{array}{l}\text { ANEMIA + } \\
\text { OUABAIN }\end{array}$ \\
\hline$\dot{\mathrm{V}} \mathrm{O}_{2}=10.04$ & $\dot{V} o_{2}=12.54$ & $\dot{\mathrm{v}} \mathrm{O}_{2}=9.04$ \\
\hline $\mathbf{m l} / \mathbf{k g} / \mathbf{m i n}$ & $\mathrm{ml} / \mathbf{k g} / \mathrm{mln}$ & $\mathrm{ml} / \mathbf{k g} / \mathrm{min}$ \\
\hline
\end{tabular}

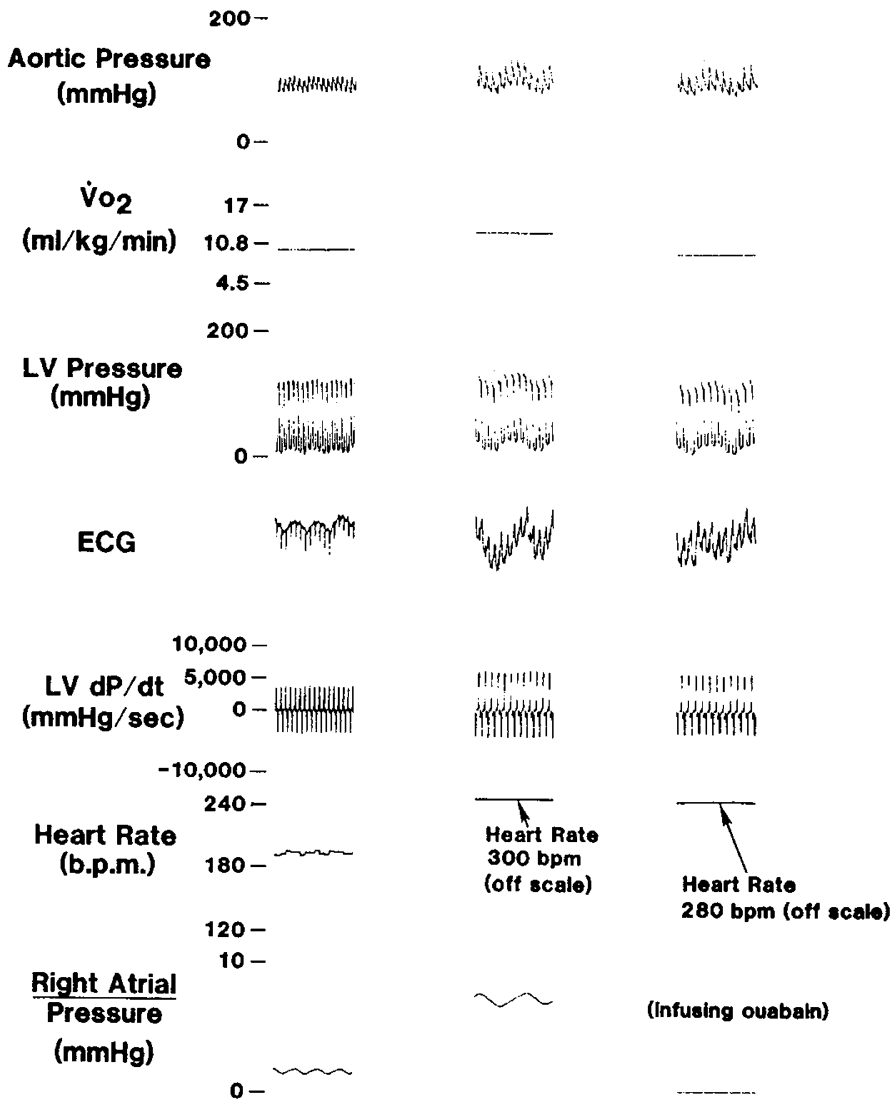

Fig. 3. Tracings from a 6-day-old lamb prior to intervention (control), following isovolemic Plasmanate exchange (anemia), and finally following ouabain infusion (anemia + ouabain). Heart rates during anemia and ouabain plus anemia were calculated manually, as the tracings are off scale. Although heart rate and LV dP/dt max remain high following induction of anemia, the anemia-associated rise in $\mathrm{VO}_{2}$ is abolished following ouabain infusion. 
clearly. Ouabain infusion reduced oxygen consumption, cardiac output, and SOT without changing $\mathrm{LV} \mathrm{dP} / \mathrm{dt}$ or the oxygen extraction ratio significantly (Table 2 ).

Figure 4 displays trends of $\mathrm{VO}_{2}$, arterial oxygen extraction, and $\mathrm{LV} \mathrm{dP} / \mathrm{dt}$ in the nine study animals under baseline conditions, during anemia, and with anemia following ouabain infusion. The ouabain-related fall in oxygen consumption is not accompanied by a further increase in oxygen extraction from the anemic state or with a change in LV myocardial function, as reflected by the $\mathrm{dP} / \mathrm{dt}$ value; the fall in $\mathrm{VO}_{2}$ is unaccompanied by a change in oxygen extraction because of a parallel fall in oxygen transport during the ouabain infusion-a reflection of the reduced cardiac output during that state.

Figure 5 relates oxygen transport to oxygen consumption in all animals studied. Points recorded during ouabain administration are cross-hatched. The reduction in oxygen consumption at low levels of oxygen transport is evident.
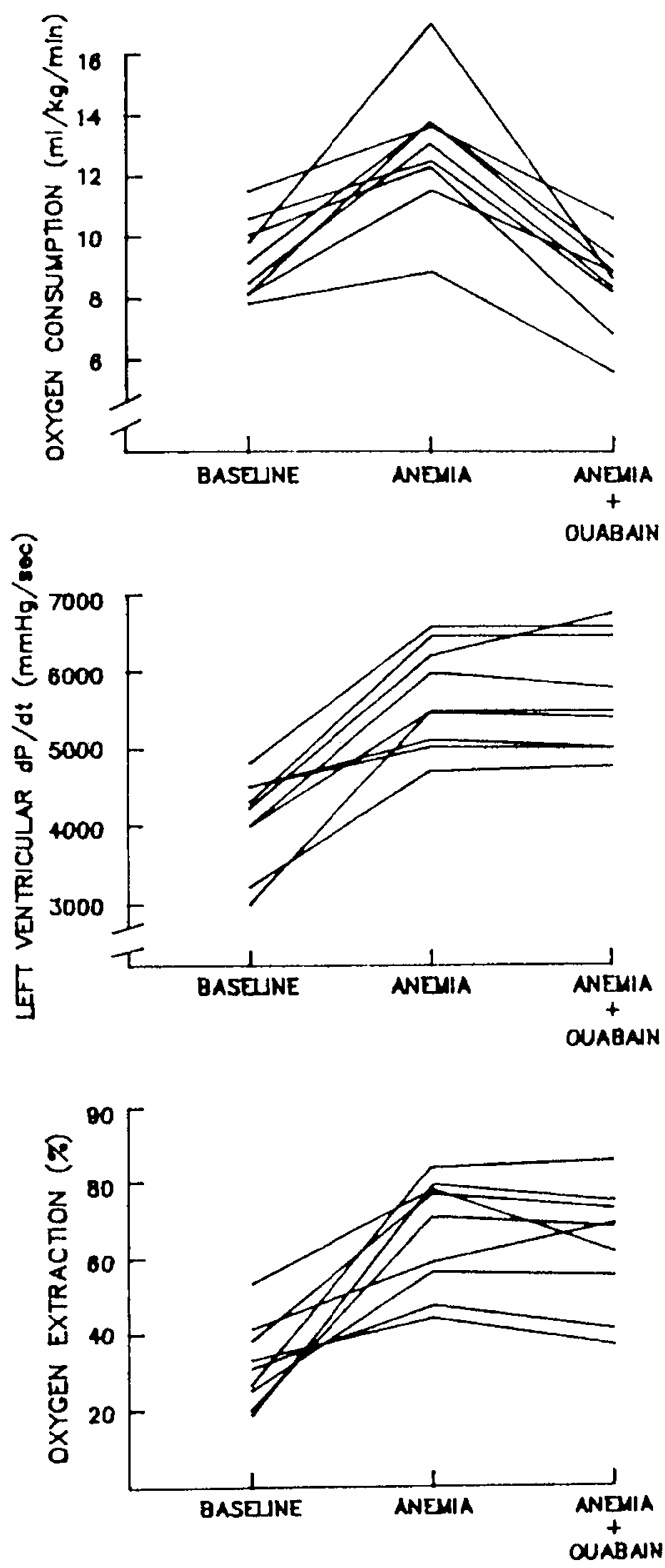

Fig. 4. Patterns of change of oxygen consumption, $L V \mathrm{dP} / \mathrm{dt}$, and arterial oxygen extraction in the nine study animals during the three experimental conditions: baseline, anemia alone, and anemia during ouabain administration.

\section{DISCUSSION}

This study was undertaken to pursue cardiac glycoside actions, other than inotropic stimulation, which might account for beneficial drug effects in infants and children with circulatory failure. Previous studies in animals $(19,20)$ and man $(15)$ have emphasized the difficulties of evaluating glycoside effects on the myocardial contractile state in some circumstances. Moreover, because clinical benefit does not always coincide with a demonstrable improvement in myocardial function (15), the possibility of a salutary noninotropic mechanism was pursued.

Our studies showed a consistent pattern of change in hemodynamic and oxygen transport variables with anemia. With hematocrit reductions from control values to levels between 10 $15 \%$, cardiac output increased, $\mathrm{LV} \mathrm{dP} / \mathrm{dt}$ and heart rate increased, and SVR decreased. Oxygen transport declined as a consequence of the reduction in arterial oxygen content.

It is noteworthy that oxygen consumption increased consistently even though the SOT decreased by approximately $40 \%$ when hematocrit was reduced to $10-15 \%$ (see Tables 1 and 2). Under most physiologic conditions in which SOT is independently reduced, oxygen consumption initially remains unchanged and then is decreased by further, more severe limitations in oxygen transport (26-28). With the decline in oxygen transport and consumption there is metabolic evidence of tissue hypoxia, reflected by an increase in arterial blood lactate concentration (27-29). For oxygen consumption to increase as it did in the present study suggests that metabolic demands were increasing with moderate anemia. The findings herein are most easily explained by the fall in oxygen transport and attendant rise in oxygen extraction stimulating the release of catecholamines which, in turn, increase cardiac output, $\mathrm{LV} \mathrm{dP/dt}$, and heart rate. The decrease in viscosity with anemia also may have contributed to the augmented cardiac output and LV dP/dt. The association of elevated levels of catecholamines with congested circulatory states has been shown in adult patients by a number of authors (30-33). In addition, catecholamines may have other extracardiac effects that stimulate calorigenesis and increase the systemic metabolic rate $(34,35)$; these extracardiac effects may contribute substantially to the initial elevation in oxygen consumption seen in the animals made anemic in this study and seen previously in a study of anesthetized adult dogs made progressively anemic (see Fig. 2, Ref. 36). Using estimates of myocardial oxygen consumption at rest, it is clear that the increase in cardiac work during anemia could not account for

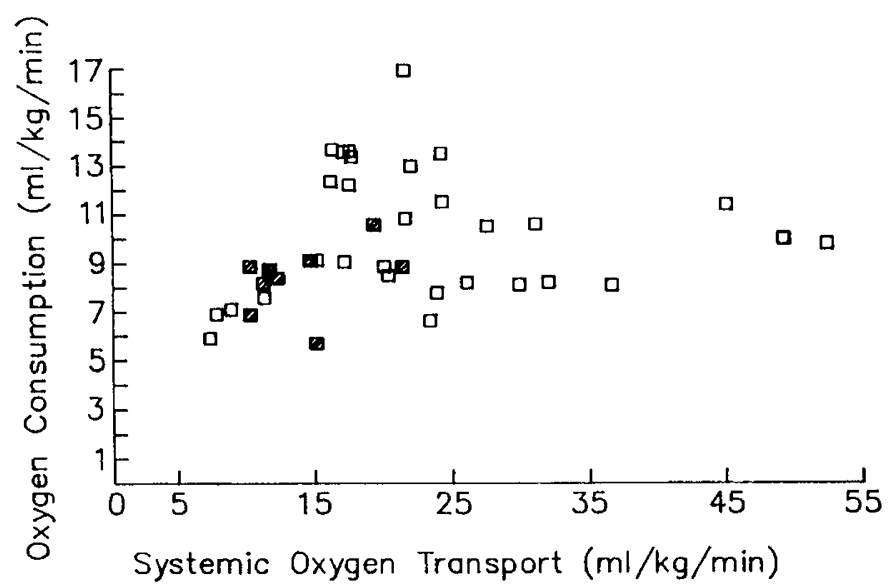

Fig. 5. The relationship of oxygen transport to consumption in all animals. The 39 points represent 27 points from nine study animals (baseline, anemia, anemia + ouabain) and 12 points from the four control animals (baseline, anemia $\times 2 \mathrm{~h}$, severe anemia). The points representing animals receiving ouabain infusion are cross-hatched. 
the $3 \mathrm{ml} \mathrm{O}_{2} / \mathrm{kg}$ min increase in whole body oxygen consumption. ${ }^{1}$

With hematocrit reductions below $10 \%$ produced in the four control group lambs reviewed in this study, cardiac function as manifested by $\mathrm{LV} \mathrm{dP} / \mathrm{dt}$ and heart rate was maintained, but cardiac output fell slightly. There is no apparent explanation for this reduction in cardiac output. The further reduction of oxygen transport with profound levels of anemia, however, is associated with reduced oxygen consumption, a further increase in the fractional oxygen extraction, and evidence of tissue hypoxia, evidenced by the significant change in base deficit (Table 1).

From control studies presented herein, it is apparent that the effects of anemia are sustained and reproducible over a 2-h period of observation; this is evidenced by the anemia-induced alterations being similar at $30-\mathrm{min}$ and 2 -h observation points (Table 1). However, the addition of ouabain infusion to the anemic preparation causes several changes in this model. Myocardial function, as evidenced by $\mathrm{LV} \mathrm{dP} / \mathrm{dt}$, heart rate, and central venous pressure, is affected little. $\mathrm{VO}_{2}$, cardiac output, and stroke work fall. SOT remains low. The pattern of reduced SOT in the presence of preserved LV function is similar to findings of clinical studies in patients with anatomic congenital cardiac lesions (such as ventricular septal defect or a large patent ductus arteriosus) associated with normal left ventricular pump function but reduced levels of systemic blood flow and, therefore, SOT $(15,21)$. These similarities reinforce the notion that cardiac glycosides may exert a portion of their beneficial effect on the circulation through sites other than the myocardium itself. Because of this possibility, the extracardiac effects of ouabain were examined in our data analysis.

There are several possible explanations for the reduction in oxygen consumption and cardiac output following ouabain infusion. 1) Circulatory function may have been reduced. We have no evidence for this as the indices we used to estimate myocardial function did not change following ouabain infusion; there were no significant changes in arterial blood gases or base buffering capacity following ouabain infusion; oxygen extraction did not rise further following ouabain infusion; and no animal underwent hemodynamic deterioration or died during the infusion period. 2) There may have been a reduction in metabolic demands to account for the ouabain-related fall in oxygen consumption. Although cardiac work was reduced by $32 \%$ following ouabain administration, the change is not high enough to account for the $35 \%$ reduction in total systemic oxygen consumption following ouabain infusion (see prior calculations in the footnote). Moreover, there is no evidence from animal observation or arterial blood gas analysis that the work of respiration changed significantly following ouabain infusion. 3) The fall in oxygen consumption could be related to altered effects of the demonstrated high levels of circulating catecholamines. In fact, catecholamine levels continued to rise following ouabain infusion to the anemic animals, but the tissue effects of the catecholamines may have been modified by the presence of ouabain. Cardiac glycosides are known to inhibit the energy requiring membrane-bound sodium-potassium ATPase pump system, an enzyme complex which is stimulated by circulating catecholamines (38). Ouabain may have acted in this case by antagonism of the peripheral catecholamine effects, thereby reducing systemic oxygen consumption, but leaving peripheral catecholamine levels elevated. This mechanism would be in concert with observations on cardiac glycoside effects in hypovolemic dogs

$$
\begin{aligned}
& \frac{15-8 \mathrm{~g}}{\mathrm{~kg}} \text { heart } \times \frac{0.8 \mathrm{mmol} \mathrm{O}}{\min \times 100 \mathrm{~g}}(37) \times \frac{22.4 \mathrm{ml} \mathrm{O}_{2}}{\mathrm{mmol} \mathrm{O}_{2}}= \\
& \qquad \frac{0.9-1.4 \mathrm{ml} \mathrm{O}}{\mathrm{kg} \times \mathrm{min}} \text { myocardial } \mathrm{VO}_{2}
\end{aligned}
$$

This value would have to increase about 3 -fold to account for the increase in whole body oxygen consumption.
(39) and in adults with respiratory distress (40). Alternatively ouabain may act through a central mechanism to reduce oxygen consumption to achievable levels of oxygen transport. The site or mechanism of this proposed central regulatory system is beyond conjecture at this time. 4) Systemic blood flow redistribution may have diverted flow from metabolically active tissues, such as brown fat. Because the flow measurements we made were global rather than regional, we cannot test this possibility with the data collected.

In summary, anemic circulatory stress in lambs increased heart rate, $\mathrm{LV} \mathrm{dP/dt,} \mathrm{cardiac} \mathrm{output,} \mathrm{central} \mathrm{venous} \mathrm{pressure,} \mathrm{arterial}$ oxygen extraction, and systemic oxygen consumption. Ouabain infusion to anemic lambs did not change oxygen extraction or alter the balance between oxygen transport and consumption, but reduced $\mathrm{VO}_{2}$, cardiac output, and stroke work. Circulating catecholamine levels rose during the period of anemia and ouabain infusion. These studies confirm an effect of cardiac glycosides that is not inotropic, but may be of benefit to subjects in high output hemodynamic states.

\section{REFERENCES}

1. Berman WR Jr 1984 Management of congestive heart failure in the neonate. Perinatology-Neonatology 8:16-26

2. Artman M, Graham TP Jr 1982 Congestive heart failure in infancy: recognition and management. Am Heart J 103:1040-1055

3. Sapin SO, Donoso E, Blumenthal S 1956 Digoxin dosage in infants. Pediatr 18:730-738

4. Marcus FT 1979 Current status of therapy with digoxin. Curr Probl Cardiol 59:5-41

5. Wettrell G 1976 Digoxin therapy in infants: A clinical pharmacokinetic study. Acta Paediatr Scand [Suppl] 257:7-26

6. Soyka LF 1972 Clinical pharmacology of digoxin. Pediatr Clin North Am 19:241-256

7. Krasula RW, Pellegrino PA, Hastreiter AR, Soyka LF 1972 Serum levels of digoxin in infants and children. J Pediatr 81:566-569

8. Wettrell G, Andersson KE 1977 Clinical pharmacokinetics of digoxin in infants. Clin Pharmacokin 2:17-31

9. Hernandez A, Burton RM, Pagtakhan RD, Goldring D 1969 Pharmacodynamics of 3 H-digoxin in infants. Pediatrics 44:418-428

10. Berman W Jr, Musselman J, Shortencarrier R 1982 The pharmacokinetics of digoxin in newborn and adult sheep. J Pharmacokin Biopharm 10:173-186

11. Berman W Jr, Musselman J 1979 Myocardial performance in the newborn lamb. Am J Physiol 237:H66-H70

12. Sahn DJ, Allen HD, Goldberg SJ, Solinger R, Meyer RA 1975 Pediatric echocardiography: a review of its clinical utility. J Pediatr 87:335-352

13. Sahn DJ, Vaucher Y, Williams DE, Allen HD, Goldberg SJ, Friedman WF 1976 Echocardiographic detection of large left to right shunts and cardiomyopathies in infants and children. Am J Cardiol 38:73-79

14. Baylen B, Meyer RA, Korfhagen J, Benzing G III, Bubb ME, Kaplan S 1977 Left ventricular performance in the critically ill premature infant with patent ductus arteriosus and pulmonary disease. Circulation 55:182-188

15. Berman W Jr, Yabek SM, Dillon T, Niland C, Corlew S, Christensen D 1983 Effects of digoxin in infants with a congested circulatory state due to a ventricular septal defect. N Engl J Med 308:363-366

16. Pinsky WW, Jacobsen JR, Gillette PC, Adams J, Monroe L, McNamara DG 1979 Dosage of digoxin in premature infants. J Pediatr 96:639-642

17. Hofstetter R, Lang D, von Bernuth G 1979 Effect of digoxin on left ventricular contractility in newborns and infants estimated by echocardiography. Eur $\mathbf{J}$ Cardiol 9:1-11

18. White RD, Lietman PS 1978 Commentary: A reappraisal of digitalis for infants with left to right shunts and "heart failure". J Pediatr 92:867-870

19. Berman W Jr, Yabek SM, Shortencarrier R 1982 The effects of ouabain in lambs with depressed myocardial function. Pediatr Res 16:357-361

20. Berman W Jr, Musselman J, Shortencarrier R 1980 The physiologic effects of digoxin under steady-state drug conditions in newborn and adult sheep. Circulation 62:1165-1171

21. Lister G, Hellenbrand WE, Kleinman CS, Talner NS 1982 Physiologic effects of increasing hemoglobin concentration in left-to-right shunting in infants with ventricular septal defects. N Engl J Med 306:502-506

22. Lister G, Hoffman JIE, Rudolph AM 1974 Oxygen uptake in infants and children: A simple method for measurement. Pediatrics 53:656-662

23. Passon PG, Peuler JD 1973 Simplified radiometric assay for plasma norepinephrine and epinephrine. Anal Biochem 51:618-631

24. Snedecor W, Cochran WG 1967 Two-way classifications. Analysis of variance. In: Statistical Methods. Iowa State University Press, Ames, IA pp 299-307

25. Hatcher JD, Chiu LK, Jennings DB 1978 Anemia as a stimulus to aortic and carotid chemoreceptors in the cat. J Appl Physiol 44:696-702

26. Adams RP, Dieleman LA, Cain SM $1982 \mathrm{~A}$ critical value for $\mathrm{O}_{2}$ transport in the rat. J Appl Physiol 53:660-664

27. Cain SM 1983 Peripheral oxygen uptake and delivery in health and disease. 
Clin Chest Med 4:139-148

28. Fahey JT, Lister G 1985 A simple method for reducing cardiac output in the conscious lamb. Am J Physiol 249:H188-H192

29. Cain SM 1985 Appearance of excess lactate in anesthetized dogs during anemic and hypoxic hypoxia. Am J Physiol 209:604-610

30. Minami M, Yasuda H, Yamazaki N, Kojima S, Nishijima H, Matsumura N, Togashi H, Koike Y, Saito H 1983 Plasma norepinephrine concentration and plasma dopamine-beta-hydroxylase activity in patients with congestive heart failure. Circulation 67:1324-1329

31. Kluger J, Cody RJ, Laragh JH 11982 The contributions of sympathetic tone and the renin-angiotensin system to severe chronic congestive heart failure: response to specific inhibitors (prazosin and captopril). Am $\mathrm{J}$ Cardiol 49:1667-1674

32. Thomas JA, Marks BH 1978 Plasma norepinephrine in congestive heart failure Am J Cardiol 41:233-243

33. Motulsky HJ, Insel PA 1982 Adrenergic receptors in man: direct identification, physiologic regulation and clinical alterations. N Engl J Med 307:18-29
34. Poyart C, Nahas GC 1966 Inhibition of catecholamine-induced calorigenesis and lipolysis by hypercapnic acidosis. Am J Physiol 211:161-168

35. Schwartz A, Allen JC, Van Winkle WB, Munson R 1974 Further studies on the correlation between the inotropic action of ouabain and its interaction with the $\mathrm{Na}^{+}, \mathrm{K}^{+}$-adenosinetriphosphatase: isolated perfused rabbit and cat hearts. J Pharmacol Exp Ther 191:119-127

36. Cain SM 1977 Oxygen delivery and uptake in dogs during anemic and hypoxic hypoxia. J Appl Physiol 42:228-234

37. Fisher DJ 1983 Left ventricular oxygen consumption and function in hypoxemia in conscious lambs. Am J Physiol 244:H664-H671

38. Sweadner KJ, Goldin SM 1980 Active transport of sodium and potassium ions-mechanism, function, and regulation. N Engl J Med 302:777-783

39. Crowell JW, Smith EE 1964 Oxygen deficit and irreversible hemorrhagic shock. Am J Physiol 206:313-316

40. Linberg SE, Applefeld JJ, Britten J, Majervs TC, Milholland AV, Feroli ER $\mathrm{Jr}$, Cowley RA 1980 Digoxin and total body oxygen consumption. Fed Proc 39:4417(abstr) 